\title{
Habitat associations and conservation status of an endemic forest dwarf chameleon (Bradypodion sp.) from South Africa
}

\author{
Walter J. Reisinger, Devi M. Stuart-Fox and Barend F.N. Erasmus
}

\begin{abstract}
We quantified habitat associations and evaluated the conservation status of a recently identified, undescribed species of dwarf chameleon, Bradypodion sp. nov. Dhlinza, endemic to scarp forest remnants in KwaZulu-Natal Province, South Africa. At the microhabitat scale the Dhlinza dwarf chameleon was found more often in forest gaps and near paths than highly disturbed edges or forest interior. Chameleon presence was not explained by forest physiognomic variables such as vine cover, shrub and tree density, or canopy cover. Presence near gaps may be better explained by the combined effects of the thermal microenvironment and food availability. The species is moderately common where
\end{abstract}

it occurs, with estimated densities of 4.7, 8.7 and 29.7 individuals per ha within forest interior, edges and gaps respectively. At the landscape scale, the chameleon occurs only in three remnant forests: the Dhlinza, Entumeni and Ongoye Forests. The species' extent of occurrence was estimated to be $88 \mathrm{~km}^{2}$ and its area of occupancy $49 \mathrm{~km}^{2}$. Based on the small area of remaining suitable habitat, this species meets the requirements for categorization as Endangered according to IUCN Red List criteria.

Keywords Abundance, Bradypodion, chameleon, edge effect, fragmentation, gaps, scarp forest, South Africa.

\section{Introduction}

Dwarf chameleons of the genus Bradypodion represent a radiation endemic to southern Africa, with 15 currently recognized species, although several new species are being described (W.R. Branch, K.A. Tolley \& C. Tilbury, unpub. data). Of the currently described species, several (B. damaranum, B. caffrum, B. nemorale, B. transvaalense and $B$. setaroi), are restricted to indigenous South African forest (Branch, 1998), and are among the few South African reptile species that are indigenous forest obligates. Forest is the least extensive biome in South Africa with the total remaining area comprising c. $7,000 \mathrm{~km}^{2}$ or $0.56 \%$ of the total land area (Low \& Rebelo, 1996; Eeley et al., 2001). This indigenous forest is highly fragmented and patchily distributed, with most remnants being small $\left(<1 \mathrm{~km}^{2}\right.$; Cooper, 1985; Low \& Rebelo, 1996) and occurring mainly in coastal areas and along the country's eastern escarpment (Midgley et al., 1997). Although there is substantial pressure on forests in terms of resource use (Lawes et al., 2004) little research on the ecology of forest communities or forest-restricted taxa has been conducted, despite disproportionately high levels of biodiversity within this

Walter J. Reisinger, Devi M. Stuart-Fox and Barend F.N. Erasmus (Corresponding author) School of Animal, Plant \& Environmental Sciences, University of the Witwatersrand, Private Bag 3, Wits 2050, South Africa. E-mail barend@biology.biol.wits.ac.za

Received 17 December 2004. Revision requested 20 April 2005. Accepted 14 June 2005. First published online 10 April 2006. biome (Geldenhuys \& MacDevette, 1989; Eeley et al., 2001). It is thus no exaggeration to suggest that South African indigenous forest is the neglected biome of South Africa.

One of the dwarf chameleon species restricted to indigenous forest is a recently identified species found in Dhlinza, Entumeni and Ongoye forest reserves (Raw, 2001) as well as in the garden environs of the town of Eshowe $\left(28.89^{\circ} \mathrm{S}, 31.46^{\circ} \mathrm{E}\right)$. Phylogenetic work by Tolley et al. (2004) showed that the dwarf chameleon found in Dhlinza Forest is not closely related to B. nemorale (12\% ND2 mtDNA divergence), the species to which these populations were previously thought to belong. Moreover, the minimum divergence for the mitochondrial ND2 gene between chameleons from Dhlinza and any other species of dwarf chameleon is $10.5 \%$, which is at the higher end of sequence divergence among any two currently recognized Bradypodion species (2-16.5\%; Tolley et al., 2004). Raw (2001) has also indicated that these chameleons should be classified as different species based on morphological characters. Not only do chameleons from Dhlinza, Entumeni and Ongoye forests represent highly genetically divergent, morphologically distinguishable populations, but they also differ in their habitat associations. Dhlinza, Entumeni and Ongoye forests are classified as scarp forest, having different floral species assemblages and physiognomic structure to higher altitude Afromontane mixed mist belt forest such as Nkandla and Qudeni where B. nemorale is found (Eeley et al., 2001). Pending their formal description and for 
the purposes of this study, chameleons occurring in Dhlinza, Entumeni and Ongoye forest will be referred to as Bradypodion sp. nov. Dhlinza or the Dhlinza dwarf chameleon.

Although the Dhlinza dwarf chameleon has yet to be formally described, its genetic distinctiveness and highly restricted range (Fig. 1) make it of immediate conservation concern. An understanding of the factors that may limit its distribution and abundance within remaining habitat patches is particularly useful for conservation management and planning. Here, therefore, we quantify the habitat associations of chameleons in Dhlinza forest. Specifically, we tested whether the abundance of Dhlinza dwarf chameleons differed between low-disturbance gaps in the forest, high-disturbance edges and intact forest. We hypothesized that chameleons should prefer gaps because gaps provide an opportunity for thermoregulation (Greenberg, 2001) whereas such forestrestricted species may be intolerant of edges bordering urban environments, which are often characterized by infestations of alien vegetation. Chameleons in Madagascar have been found to be more abundant in forests of low disturbance than in patches of high disturbance (Jenkins et al., 2003). We also estimated the density of this chameleon in the Dhlinza forest and the potential habitat remaining in KwaZulu-Natal. Based on these results, we assess the conservation status of this species in accordance with IUCN guidelines (IUCN, 2001).

\section{Study species and site}

Dwarf chameleons of the genus Bradypodion are small, insectivorous, strictly arboreal reptiles and generally have allopatric, restricted ranges. All species are viviparous, produce up to two litters a year, and reach sexual maturity in 1-2 years (Branch, 1998). At night, chameleons roost on peripheral vegetation (tips of vines and leaves), presumably to avoid predators.

We surveyed chameleons in the Dhlinza Forest, near Eshowe in KwaZulu-Natal (Fig. 1). The protected, 265 ha Dhlinza forest is a remnant indigenous scarp forest (Eeley et al., 2001; Lawes et al., 2004). It is partly fragmented and surrounded by suburban development and sugarcane fields. The forest occurs at an altitude of $500 \mathrm{~m}$, with a rainfall of $c .1,200 \mathrm{~mm}$ per annum.

\section{Methods}

\section{Survey techniques and sampling design}

We conducted nocturnal surveys (19.30-23.00) from 22 March to 20 April 2004, a period in which chameleons are active, using a distance sampling protocol that has been used in previous studies of chameleon population status and density (Brady \& Griffiths, 1999; Jenkins et al., 1999, Jenkins et al., 2003). To obtain perpendicular distance from the transect we recorded the horizontal distance to the chameleon and the vertical perch height and

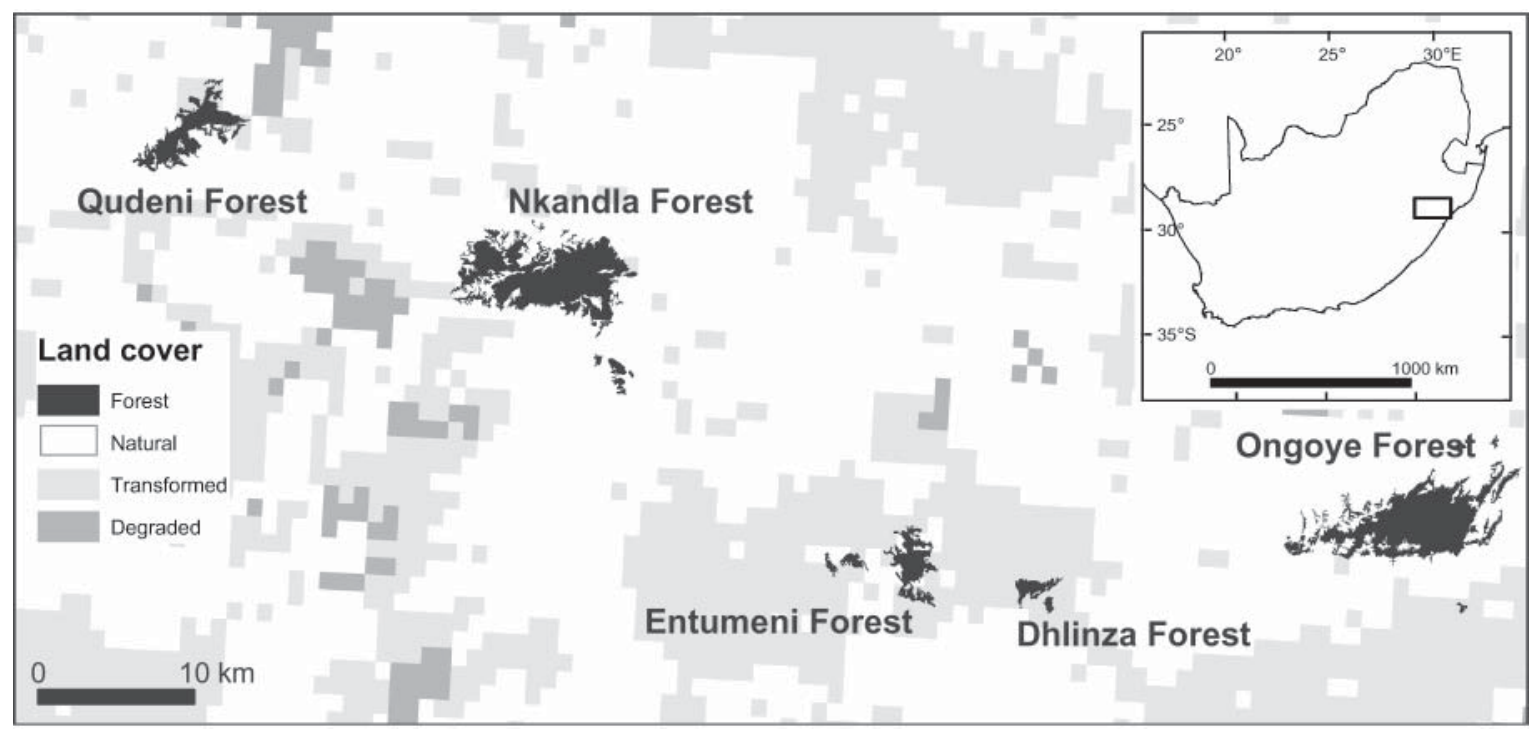

Fig. 1 Study location (Dhlinza Forest) and associated indigenous forest remnants in southern Zululand, South Africa (Mucina et al., 2004). The rectangle in the inset map indicates the area of study; detailed location maps are available on request. Entumeni, Dhlinza and Ongoye are scarp forest, whereas Qudeni and Nkandla are Afromontane forest. The available land cover information dates from 1994 (Fairbanks et al., 2000), and does not reflect the current extent of transformation and degradation but does give an indication of the isolated nature of these forest fragments. The natural land cover class refers to natural vegetation (not including forest), the transformed class refers to agriculture, forestry and built up areas, and the degraded class refers to areas of artificially low vegetation cover, i.e. overgrazed areas (see Fairbanks et al., 2000, for more details). 
calculated the length of the hypotenuse. Our vertical detection ceiling was $10 \mathrm{~m}$ rather than $6 \mathrm{~m}$, as used in other studies (Jenkins et al., 1999; Jenkins et al., 2003), because we used a powerful hand-held spotlight enabling good visibility.

We surveyed 32 line transects, each $100 \mathrm{~m}$ long. Transects were categorized as (1) along the forest edge (13 transects), (2) along edges/gaps within the forest (e.g. tree-fall gaps, small clearings, paths $<3 \mathrm{~m}$ wide; seven transects), and (3) within the forest interior (12 transects). Edge transects were generally highly disturbed, characterized by an abrupt transition between forest and suburban environment or tarmac road, and often with infestations of dense, alien vegetation. Gap transects were less disturbed, largely free of alien vegetation, and characterized by small breaks in intact forest. Transects were placed to maximize coverage and ensure adequate representation of the forest, and were placed a minimum of $50 \mathrm{~m}$ apart to preclude recaptures. We moved slowly (c. $1 \mathrm{~m}$ per minute; 1.5 hours per transect) along each transect, systematically searching the vegetation for roosting chameleons.

Where possible we captured chameleons with a $5 \mathrm{~m}$ telescopic fibreglass rod by inserting the tip of the rod underneath the chameleon and lifting it up, thereby forcing it to cling onto the rod. For each chameleon captured we recorded (1) snout-vent length (SVL), in mm, using callipers, (2) sex, indicated by the presence of hemipenal bulges in males, (3) age class (adult or juvenile), (4) perch height (m), and (5) height to the first fork of the perch plant $(\mathrm{m})$. We noted whether the perch plant was a vine or a tree. We released the chameleon where it was captured and marked the spot with flagging tape.

The following day we returned to transects surveyed the previous night and marked $10 * 10 \mathrm{~m}$ plots every $25 \mathrm{~m}$ along the transects. If the location of a chameleon did not fall within a plot we marked out additional $10 \times 10 \mathrm{~m}$ plots surrounding the location of each individual. Within these plots we recorded 11 microhabitat variables (Table 1). Thus, for each transect we measured microhabitat variables for plots with chameleons, and up to four plots without chameleons. This enabled us to determine which, if any, microhabitat characteristics were associated with the presence or absence of chameleons within the forest.

\section{Habitat associations}

To determine which microhabitat variables were associated with probability of chameleon occurrence, we first converted absolute number of chameleon captures to presence and absence for each plot $(n=131)$ within each transect. To account for potential spatial autocorrelation of plots within transects we applied a generalized estimating equation (Liang \& Zeger, 1986), which is a specialized general linear model (GLM) that accounts for the correlation between observations in regression models. Plot was specified as the repeated measure within each transect, and the independent variables are given in Table 1. Statistical analyses were performed using PROC GENMOD in SAS version 9.1 (SAS Institute, 2003). Model selection was by backward elimination with a criterion for remaining in the model of $\mathrm{P}<0.1$.

\section{Extent of suitable habitat}

To identify the potential distribution of the species we estimated the extent of scarp forest left in southern Zululand, and the distances between and sizes of remnants of this forest type using ArcGIS (ESRI, 2003) and the most recent vegetation coverage for southern Africa (Mucina \& Rutherford, 2004). This information provided

Table 1 Microhabitat variables recorded within $10 * 10 \mathrm{~m}$ habitat plots along each transect in the Dhlinza scarp forest, KwaZulu-Natal, South Africa.

\begin{tabular}{|c|c|}
\hline Variable & Description \\
\hline Transect type & Edge, gap or forest interior. \\
\hline Distance to nearest gap $(\mathrm{m})$ & $\begin{array}{l}\text { Distance to tree fall gap or path; if no gap was present within } 15 \mathrm{~m} \text {, a nominal } 18 \mathrm{~m} \text { was } \\
\text { recorded. }\end{array}$ \\
\hline Distance to forest edge $(\mathrm{m})$ & Calculated based on GPS coordinates for each plot, using ArcGIS (ESRI, 2003). \\
\hline Canopy cover $(\%)$ & Using a spherical densiometer. \\
\hline Canopy height & 1 , up to $5 \mathrm{~m} ; 2,5-10 \mathrm{~m} ; 3,10-15 \mathrm{~m} ; 4, \geq 15 \mathrm{~m}$. \\
\hline Tree circumference at breast height $(\mathrm{cm})$ & $\begin{array}{l}\text { Woody vegetation of } 5 \mathrm{~m} \text { or more in height; circumference obtained with a measuring tape; } \\
\text { converted to woody stem density per quadrat. }\end{array}$ \\
\hline Number of trees & Woody vegetation $>5 \mathrm{~m}$ in height. \\
\hline Number of shrubs & Vegetation $1-5 \mathrm{~m}$ in height. \\
\hline Vine cover estimate & $\begin{array}{l}\text { 1, } 0-25 \% ; 2,25-50 \% ; 3,50-75 \% ; 4,75-100 \% \text {; vines were classified as Low Vine (occurring in the } \\
\text { lower } 5 \text { m stratum of forest), and Tall Vine (occurring above } 5 \mathrm{~m} \text { ). }\end{array}$ \\
\hline Vertical visibility (m) & $\begin{array}{l}\text { Visibility from the observer on the transect to the canopy. Estimated using the } 8 \mathrm{~m} \text { long noosing } \\
\text { rod as a proxy, whereby the rod's length was used to judge visibility. }\end{array}$ \\
\hline Horizontal visibility (m) & Horizontal distance from the transect into the forest; estimated using the noosing rod. \\
\hline
\end{tabular}


area values of the extent of occurrence and area of occupancy (IUCN, 2001). We measured extent of occurrence using a minimum convex polygon, and estimated area of occupancy as the area of scarp forest within the extent of occurrence.

\section{Density, population size and conservation status}

Density estimates were derived using the software Distance v. 4.1 (Thomas et al., 2004). One of the main assumptions of distance sampling is that transects are placed randomly such that habitat types are sampled proportionally to their occurrence. If this assumption is met density estimates can be extrapolated to estimate population size (Buckland et al., 2001). As our transects were not randomly distributed, we estimated density for each habitat type (gaps, edges and forest interior) and multiplied it by the area represented by that transect type (see below) then summed the three separate abundance estimates to obtain an estimate of population size. Low numbers of individuals precluded reliable calculation of a separate detection function (and therefore density estimate in Distance) for each habitat type. Instead, we simply multiplied the mean adult density by the proportion of individuals found in habitat type A divided by the proportion of habitat type A surveyed. For instance, only $15 \%$ of individuals were found in forest interior yet forest interior represented $37.5 \%$ of transects surveyed. Thus, density in forest interior $=$ mean adult density $* 0.15 /$ 0.375 . This method of estimating density for each transect type implicitly assumes that detection functions are similar between transect types. There were no significant differences among transect types in chameleon perch height or horizontal distance from the transect, suggesting that detection functions should be similar.

Area of edge habitat was estimated as the length of the forest perimeter (derived from the vegetation coverage) multiplied by a width of $4.5 \mathrm{~m}$ (mean horizontal visibility). We used the estimate of Oribi \& Lawes (2004) of $7.8 \%$ for the area of forest under natural gap phase. This estimate was derived for coastal Pondoland scarp forest in South Africa. The proportion of forest interior was calculated as the remaining area not composed of edges and gaps.

Results of the habitat selection study, density estimate and information on extent of occurrence and area of occupancy were used to determine conservation status in accordance with IUCN Red List Criteria version 3.1 (IUCN, 2001).

\section{Results}

We found a total of 29 chameleons, of which 18 were adults (nine males, nine females), nine were juveniles (five males, four females), and four were not captured and therefore could not be sexed (two of these were clearly adults judging from their large size). Seventeen chameleons were found perching on vines and 12 on the leaves of various indigenous tree species. On average chameleons occurring at or near gaps were found at a mean distance of $2.18 \pm$ SE $0.57 \mathrm{~m}$ from a gap. We found chameleons at an average perch height of $4.2 \pm$ SE $0.45 \mathrm{~m}$ above ground, and $2.97 \pm$ SE $0.41 \mathrm{~m}$ from the edge of a transect.

The average vertical and horizontal visibilities along transects were $6.1 \pm \mathrm{SE} 0.20 \mathrm{~m}$ and $4.5 \pm \mathrm{SE} 0.23 \mathrm{~m}$, respectively. The chameleons we found thus fell well within this range of visibility. Furthermore, neither the horizontal distance from transects nor the perch height of captured chameleons differed significantly between the three habitat types (one-way ANOVA, $F_{2}=0.14$, $\mathrm{P}=0.87$ for horizontal distance and $F_{2}=0.47, \mathrm{P}=0.63$ for perch height).

\section{Habitat associations}

Habitat type significantly affected the probability of chameleon presence (Table 2). Specifically, gap transects were significantly more likely to have chameleons present than either forest interior transects $(F=8.28$, $\mathrm{df}=1, \mathrm{P}=0.004)$ or edge transects $(F=4.68, \mathrm{df}=1$, $\mathrm{P}=0.031)$. We found on average $2.0 \pm$ SE 0.5 chameleons per gap transect, $0.8 \pm$ SE 0.3 chameleons per forest edge transect, and only $0.4 \pm$ SE 0.2 chameleons per transect in the forest interior. There was a weak trend for the probability of chameleon occurrence to increase with decreasing distance to the nearest gap, although this relationship was not significant at $\mathrm{P}<0.05$ (Table 2 ). No other variables were retained within the final model.

\section{Extent of suitable habitat}

Only 28,400 ha of scarp forest remain in KwaZuluNatal. The closest remnants to Dhlinza are the Entumeni (829 ha) and Ongoye (3,445 ha) forest reserves $(6.2 \mathrm{~km}$ and $16.8 \mathrm{~km}$ in a direct line from Dhlinza, respectively). There are no other forest remnants in the area that could constitute available habitat (Fig. 1). The extent of chameleon occurrence was $88 \mathrm{~km}^{2}$ and the area of occupancy was $49 \mathrm{~km}^{2}$.

Table 2 Factors predicting presence of chameleons. Only variables remaining within the final model are shown.

\begin{tabular}{lrcr}
\hline Independent variable & $F$ & $\mathrm{df}$ & \multicolumn{1}{c}{$\mathrm{P}$} \\
\hline Intercept & 14.37 & & $<0.001$ \\
Distance to gap & 2.82 & 1 & 0.093 \\
Transect type & 6.68 & 2 & 0.036 \\
\hline
\end{tabular}




\section{Density and population size}

The mean density of chameleons was $11.8 \pm$ SE 4.3 chameleons per ha for adult chameleons, and 19.2 \pm SE 5.5 chameleons per ha for all observed chameleons. Density for forest interior was estimated as $11.8 * 0.15 / 0.38=4.7$ individuals per ha. Similarly, density for gaps was $11.8 * 0.55 / 0.22=29.7$ individuals per ha, and density for edges was $11.8 * 0.30 / 0.41=8.7$ individuals per ha. Gaps, edges, and forest interior were estimated to comprise $7.8,3.4$ and $88.8 \%$ of the area of Dhlinza forest (265 ha) respectively. Based on these estimates of density for each transect type and the area occupied by each, we calculated the projected population size for Dhlinza to be 2,453 \pm SE 894 adult chameleons.

\section{Discussion}

\section{Habitat preferences}

The Dhlinza dwarf chameleon prefers gaps within scarp forest. These gaps are typically minor paths and tree fall gaps, and thus represent only moderately disturbed forest. The higher probability of chameleon presence near gaps was not an artefact of greater visibility or ease of sighting chameleons in this habitat type because neither visibilities nor the horizontal distances and perch heights of captured chameleons differed significantly between the three habitat types. Jenkins et al. $(1999,2003)$ similarly found that chameleons in Madagascar were more abundant in forests of low disturbance than in patches of high disturbance and that some species were more common on path transects than forest-interior transects. The edges of the forest were often highly disturbed habitat and characterized by dense vegetation (often dense vines), with high levels of invasive alien vegetation, predominantly Lantana camara and Chromolaena odorata; chameleons were not often found in such overgrown areas. This indicates that this dwarf chameleon species prefers naturally disturbed habitats in scarp forest.

Neither shrub or tree density, nor vine densities, predicted chameleon presence. Although chameleons were often found roosting on vines, they were found as often on the leaves of trees or shrubs. As almost all plots had a combination of shrubs, trees, and low and high vines, the exact proportions of these structural microhabitat features do not appear to be a limiting factor for chameleons. Similarly, canopy cover may not explain chameleon presence because many of the gaps within the forest did not involve large canopy gaps; minor paths still had a largely intact canopy above. Thus the effect of transect type appears to be independent of differences in any single aspect of habitat structure between gaps, edges and forest interior. An alternative possibility is that the preference of chameleons for gaps may be associated with other factors such as food availability or thermal properties rather than the microhabitat features measured. For example, forest gaps have higher arthropod abundance, in large part due to the higher light levels, which increase primary productivity (Murcia, 1995; Greenberg, 2001). Furthermore, forest gaps may represent the best trade-off between thermal environment, food availability, availability of perches and protection from predators.

\section{Conservation status}

This study suggests that the Dhlinza dwarf chameleon should be categorized as Endangered based on IUCN criteria (IUCN, 2001) B1ab(i) + 2a; i.e. the extent of occurrence is $<5,000 \mathrm{~km}^{2}$, highly fragmented and declining, and the area of occupancy is $<500 \mathrm{~km}^{2}$ and also highly fragmented. Apart from Dhlinza the only other patches of suitable habitat are the Entumeni and Ongoye reserves (Fig. 1). The extent of occurrence $\left(88 \mathrm{~km}^{2}\right)$ is considerably lower than the cut-off limit of $5,000 \mathrm{~km}^{2}$ for Endangered (IUCN, 2001). Furthermore, a large component of the Dhlinza Forest is made up of habitat that is not suitable to these dwarf chameleons.

Despite the high degree of habitat fragmentation and the small area of occupancy, these chameleons appear to be reasonably common where they occur. The density estimates that we obtained were in the mid-lower range of density estimates obtained for various chameleon species from Madagascar (Brady et al., 1999; Jenkins et al., 1999). In addition, we obtained an initial population estimate of 1,560-3,350 chameleons for Dhlinza forest but we are not aware of any analysis of minimum viable population size for chameleons. Although chameleons have relatively high fecundity, they experience high mortality and anecdotal evidence suggests that population size may fluctuate dramatically between years (Branch, 1998). Given these considerations and the limited mobility of chameleons, which has implications for finding mates, any conclusions regarding the viability of the Dhlinza population would be premature.

Our density and population size estimates are initial estimates that should be treated as indicative only. Ideally surveys should be conducted within Entumeni and Ongoye forests and the resulting data used to obtain independent density estimates, estimate total population size and to cross-validate the habitat selection model for this taxon (Guisan \& Zimmermann, 2000). However, results of this study provide important initial baseline estimates of habitat preferences and density that are independent of the taxonomic designation of the Dhlinza population. Furthermore, there is strong evidence that chameleons found in Dhlinza, Ongoye and Entumeni scarp forests constitute a separate species that qualifies for Endangered status based on geographic features (extent of occurrence and area of occupancy), and should 
receive this status following its formal taxonomic description. Our study highlights the need to protect and maintain indigenous forest remnants, for which dwarf chameleons could serve as a flagship species.

\section{Acknowledgements}

We thank Martin Whiting, Mike Lawes and an anonymous reviewer for helpful comments on the manuscript, Graham Chennells for sponsorship, and Darryn Watkins and Dumisani Mpila for field assistance. We are also grateful to Gunnar Marby and Dennis Eckard for logistic advice. This work was supported by an Honours Grant from the School of Animal, Plant \& Environmental Sciences to WJR, a University of the Witwatersrand Research Grant to BFNE and UNESCO-L'Oreal Grant for Women in Science to DMSF. Ezemvelo KZN Wildlife permit $4840 / 2003$.

\section{References}

Brady, L.D. \& Griffiths, R.A. (1999) Status Assessment of Chameleons in Madagascar. IUCN Species Survival Commission, IUCN, Gland, Switzerland and Cambridge, UK.

Branch, W.R. (1998) Field Guide to Snakes and other Reptiles of Southern Africa, 3rd edition. Ralph Curtis Books, Sanibel Island, Florida.

Buckland, S.T., Anderson, D.R., Burnham, K.P., Laake, J.L., Borchers, D.L. \& Thomas, L. (2001) Introduction to Distance Sampling: Estimating Abundance of Biological Populations. Oxford University Press, Oxford, UK.

Cooper, K.H. (1985) The Conservation Status of Indigenous Forests in Transvaal, Natal and O.F.S., South Africa. Wildlife Society of South Africa, Durban, South Africa.

Eeley, H.A.C., Lawes, M.J. \& Reyers, B. (2001) Priority areas for the conservation of subtropical indigenous forest in Southern Africa: a case study from KwaZulu-Natal. Biodiversity and Conservation, 10, 1221-1246.

ESRI (2003) ArcGIS @ 1 1999-2003. ESRI, Redlands, USA.

Fairbanks, D.H.K., Thompson, M.W.M., Vink, D.E., Newby, T.S., van den Berg, M. \& Everard, D.A. (2000) The South African land-cover characteristics database: a synopsis of the landscape. South African Journal of Science, 96, 69-82.

Geldenhuys, C.J. \& MacDevette, D.R. (1989) Conservation status of coastal and montane evergreen forest. In Strelitzia 1: Biotic Diversity in Southern Africa (ed. B.J. Huntley), pp. 224-238. Oxford University Press, Cape Town, South Africa.

Greenberg, C.H. (2001) Response of reptile and amphibian communities to canopy gaps created by wind disturbance in the southern Appalachians. Forest Ecology and Management, 148, 135-144.

Guisan, A. \& Zimmermann, N.E. (2000) Predictive habitat distribution models in ecology. Ecological Modelling, 135, 147-186.

IUCN (2001) 2001 Categories and Criteria (version 3.1). IUCN, Gland, Switzerland [http:/ / www.redlist.org/info/ categories_criteria2001.html, accessed 1 November 2005].

Jenkins, R.K.B., Brady, L.D., Bisoa, M., Rabearivony, J. \& Griffiths, R.A. (2003) Forest disturbance and river proximity influence chameleon abundance in Madagascar. Biological Conservation, 109, 407-415.
Jenkins, R.K.B., Brady, L.D., Huston, K., Kauffmann, J.L.D., Rabearivony, J., Raveloson, G. \& Rowcliffe, J.M. (1999) The population status of chameleons within Ranomafana National Park, Madagascar, and recommendations for future monitoring. Oryx, 33, 38-46.

Lawes, M.J., Midgley, J.J. \& Chapman, C.A. (2004). South Africa's forests: the ecology and sustainable use of indigenous timber resources. In Indigenous Forests and Woodlands in South Africa: Policy, People and Practice (eds M.J. Lawes, H.A.C. Eeley, C.M. Shackleton \& B.G.S. Geach), pp. 31-75, University of KwaZulu-Natal Press, Durban, South Africa.

Liang, K.-Y. \& Zeger, S.L. (1986) Longitudinal data analysis using generalized linear models. Biometrika, 73, 13-22.

Low, A.B. \& Rebelo, A.G. (1996) Vegetation of South Africa, Lesotho and Swaziland. Department of Environmental Affairs and Tourism, Pretoria, South Africa.

Midgley, J.J., Cowling, R.M., Seydack, A.H.W. \& Van Wyk, G.F. (1997) Forest. In Vegetation of Southern Africa (eds R.M. Cowling, D.M. Richardson \& S.M. Pierce), pp. 278-299. Cambridge University Press, Cambridge, UK.

Mucina, L. \& Rutherford, M.C. (2004) Vegetation Map of South Africa, Lesotho and Swaziland: Shapefiles of Basic Mapping Units, Beta Version 4.0. National Botanical Institute, Cape Town, South Africa.

Murcia, C. (1995) Edge effects in fragmented forests: implications for conservation. Trends in Ecology \& Evolution, 10, 58-62.

Obiri, J.A.F. \& Lawes, M.J. (2004) Chance versus determininsm in canopy gap regeneration in coastal scarp forest in South Africa. Journal of Vegetation Science, 15, 539-547.

Raw, L.R.G. (2001) Bradypodion from eastern South Africa. MSc thesis, University of KwaZulu-Natal, Pietermaritzburg, South Africa.

SAS Institute (2003) The SAS System For Windows. SAS Institute Inc., Cary, USA.

Thomas, L., Laake, J.L., Strindberg, S., Marques, F.F.C., Buckland, S.T., Borchers, D.L., Anderson, D.R., Burnham, K.P., Hedley, S.L., Pollard, J.H. \& Bishop, J.R.B. (2004) Distance 4.1. Release 2. Research Unit for Wildlife Population Assessment, University of St. Andrews, UK.

Tolley, K.A., Tilbury, C., Branch, W.R. \& Matthee, C.A. (2004) Bradypodion (Squamata: Chamaeleonidae). Molecular Phylogenetics and Evolution, 30, 354-365.

\section{Biographical sketches}

Walter Reisinger is an ecologist with broad interests in sustainable resource use and conservation. He is currently working as a field ranger.

Devi Stuart-Fox's principal area of research is behavioural and evolutionary ecology. She has conducted extensive fieldwork on dwarf chameleons in South Africa to examine the interaction between natural and sexual selection in the evolution of chameleon collocation and colour change.

Barend Erasmus has broad interests in biodiversity, climate change, systems ecology and quantitative conservation biology. His current research focuses on the different scales at which drivers of global change operate, with a view to improve climate change impact predictions and inform conservation adaptation options. 